\title{
WestVirginiaUniversity
}

THE RESEARCH REPOSITORY @ WVU

West Virginia Agricultural and Forestry Experiment

Davis College of Agriculture, Natural Resources

Station Bulletins

And Design

$1-1-1952$

\section{Retailing eggs in West Virginia stores}

Norman Nybroten

Follow this and additional works at: https://researchrepository.wvu.edu/ wv_agricultural_and_forestry_experiment_station_bulletins

\section{Digital Commons Citation}

Nybroten, Norman, "Retailing eggs in West Virginia stores" (1952). West Virginia Agricultural and Forestry Experiment Station Bulletins. 354.

https://researchrepository.wvu.edu/wv_agricultural_and_forestry_experiment_station_bulletins/354

This Bulletin is brought to you for free and open access by the Davis College of Agriculture, Natural Resources And Design at The Research Repository @ WVU. It has been accepted for inclusion in West Virginia Agricultural and Forestry Experiment Station Bulletins by an authorized administrator of The Research Repository @ WVU. For more information, please contact ian.harmon@mail.wvu.edu. 


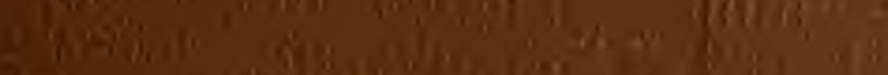
(12.

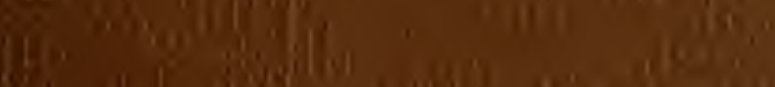

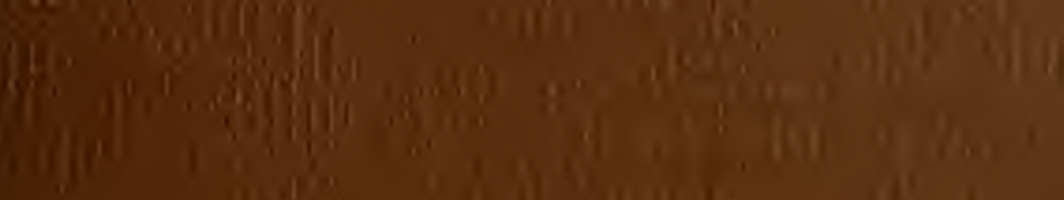

sonst (स)ा" 10. I (6) 1.

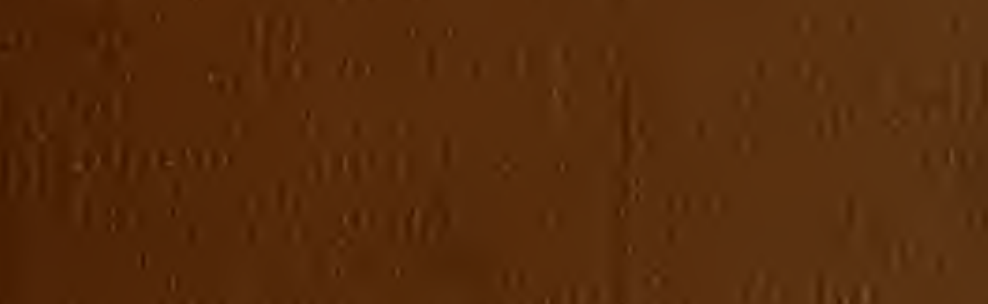
min

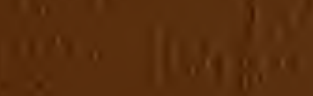
III Intas in 1 . 4in

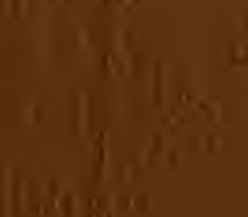
10 (1)

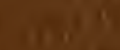

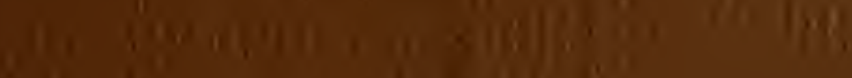

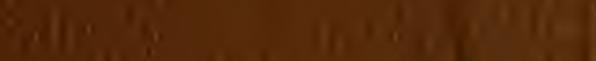

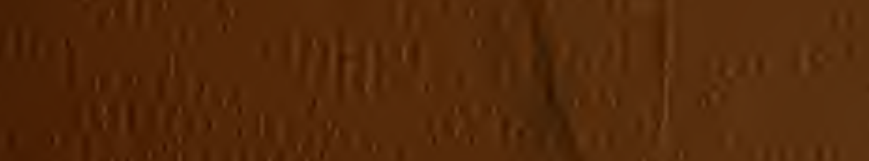
1.

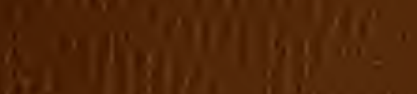

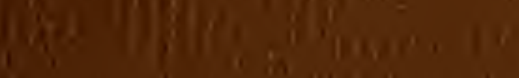
1)

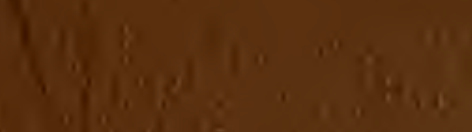

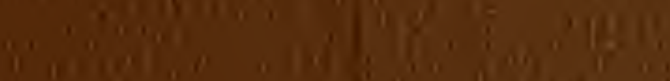

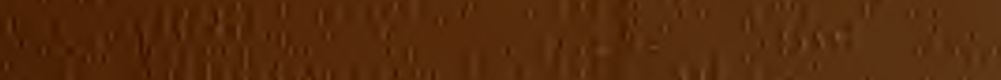

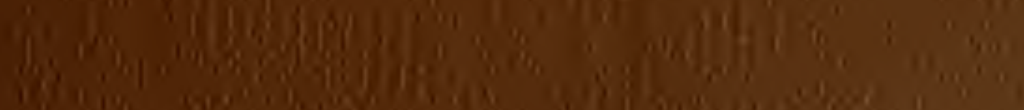

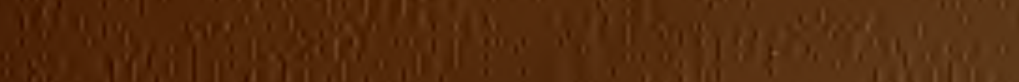
las Sy:

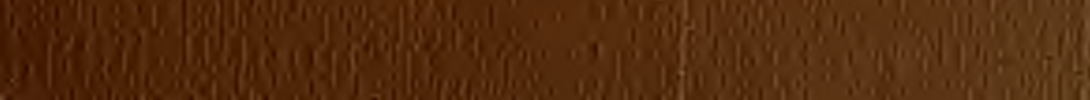


Digitized by the Internet Archive in 2010 with funding from Lyrasis Members and Sloan Foundation 


\section{RETAILING EGGS}

In West Virginia Stores

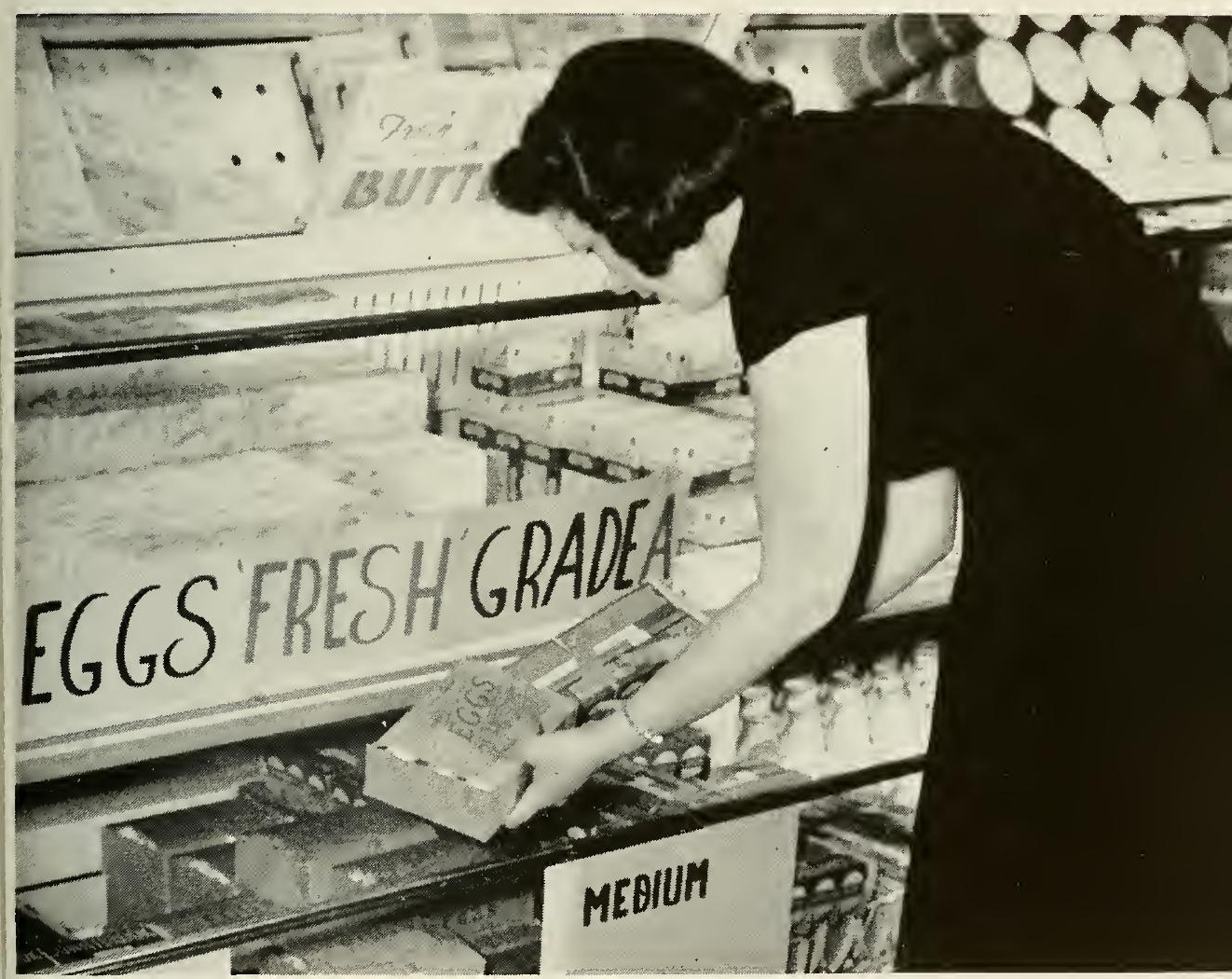

BULLETIN 354

JUNE 1952

WEST VIRGINIA UNIVERSITY AGRICULTURAL EXPERIMENT STATION 
NORMAN NYBROTEN, author of Retailing Eggs in West Virginia Stores, is an Agricultural Economist at the West Virginia University Agricultural Experiment Station and Prolessor of Agricultural Economics in the College of Agriculture, Forestry, and Home Economics.

\author{
West Virginia University \\ Agricultural Experinent Station \\ College of Agriculture, Forestry, and Home Economicis
}

H. R. VARney, Director

MORGANTOWN 


\section{Preface}

Under the financial support of the Research and Marketing Act of 1946, a regional project was undertaken for the Northeast states. In this project, 1,500 retail stores were sampled in 1949 to study retail egs marketing. Of the 1,500 stores, 53 were to be taken from West Virginia. Since a large part of the expense of carrying on a research project of this type is one of training field workers and setting up the system of procedure, it was deemed that it would not cost appreciably more to take records from enough retail stores to get a somewhat representative picture of retail egg marketing in West Virginia. Although about 500 West Virginia retail establishments were visited, the number of stores used in any given comparison was determined by the nature of the data received.

A survey study of this type must necessarily depend on the wholehearted cooperation of those furnishing information. Virtually all of the retailers visited in the study were both cordial and cooperative and it is believed that they generally gave reliable information. Retail grocers' associations were especially helpful in some of the communities in presenting the study locally as were also local newspapers. Charles Blake, in charge of egg inspection for the West Virginia State Department of Agriculture, contributed much to the study by giving training to egg inspectors working on the study.

Homer C. Evans, Assistant Agricultural Economist, Agricultural Experiment Station, West Virginia University, supervised the field work and egg grading, and Ronald Bird, lormerly Assistant Agricultural Economist, Agricultural Experiment Station, West Virginia University, supervised compilations and tabulations. 


\section{Summary}

1. A sample of 179 retail stores inclicated that the average retail store in West Virginia sold less than seventy-four dozen eggs in a typical week in the summer of 1949.

2. During the hot-weather season of 1949 an average retail food store in West Virginia sold 5.1 dozen eggs for each $\$ 100$ of gross sales.

3. Few stores in the State handled eggs in any form other than in the shell. Some sold frozen eggs "on order" to bakeries and largerdemand institutions.

4. About two-thirds of the retail stores sold all their eggs in paper bags.

5. About half of all the eggs handled by the stores sampled were retailed in paper bags compared with less than one-fifth in the twelve Northeast states.

6. In the bulk of the stores, the egg quality was higher in stores that sold more eggs.

7. Several stores paid for eggs "in trade" and handled them without any margin.

8. Margins taken by selt-service stores were somewhat higher than in counter-service stores.

9. Only two-thirds of the eggs offered were Grade A quality.

10. About one-third of the retailers in places of less than 2,500 people stated that they were receiving Grade A eggs. It seems their statements were not based on specific stanclards.

11. Eggs kept under refrigeration in the store were generally of higher quality than those not kept under refrigeration.

12. The percentage of eggs of Grade A or AA quality decreased generally about six points for each added day the eggs had been held in the store.

13. The size of the eggs retailed in West Virginia stores was similar to that in the Northeast but the quality was lower.

14. Nearly all the stores met the requirements for the total dozen weights set as standards for the classes of eggs they were advertising. Few retailers were concerned about individual-egg weight standards. 


\section{Retailing Eggs in West Virginia Stores}

NORMAN NYBROTEN

In West Virginia a large percentage of eggs for table use move through both irregular and temporary marketing channels. Althougin there are well-established channels and dealers around the larger cities in the State, in the smaller cities and rural areas there is a less fixed pattern for marketing eggs. West Virginia has a real problem in egg marketing because the pattern is not fixed. One of the reasons for this is that production varies from one area to another and from season to season. Since there has been an abnomally good opportmity for jobs in the mines and industry, many people who were part-time poultry farmers have now sold their flocks. This creates a problem for egg handlers and retail stores because they cannot go into a given area and be sure of a regular egg supply. A previous study in West Virginia showed that only a very few egg dealers who picked up eggs at the farm had been in operation over a long period. One of the most serious problems in supply is that eggs are scarce during the summer months.

The problem of obtaining quality is always present in egg marketing. One of the primary purposes of this study was to determine the quality of eggs available to consumers in the retail stores during the summer.

Another major purpose of this study was to learn how retailers merchandise eggs and to learn whether or not their merchandising methods had any effect on the demand for eggs and on the cost of handling eggs. It was hoped that some retail practices could be recommended from studying merchandising practices in the store.

Considerable interest seems to have developed on the question of how West Virginia eggs compare with those of other areas. Because figures were immediately available from the regional study of the Northcast, West Virginia has been compared with the Northeast in several instances throughout this bulletin.

It should be borne in mind that this study applies to conditions $i_{i}$ the summer of 1949 and may not be representative of other seasons or other years. 


\section{Wethods and Terms Used}

A random sample of retail lood stores in West Virginia was drawn in a manner that gave each store in the State an equal chance to be included in the sample. The twenty-five or thirty largest stores in the State were not adequately sampled through this chance method. 'This means that averages of volumes for all stores shown for the State by this sample are probably slightly lower than would have resulted from a complete enumeration of all the stores.

Retailers in the sample stores were interviewed with the aid of a questionnaire in the summer of 1949. Questions pertinent to classifying stores, learning business volumes, egg volumes, handling and merchandising practices for eggs, and opinions related to eggs were asked.

The eggs were inspected by specially trained persons. If, for any reason, a group of eggs in a store seemed different from other eggs for sale-such as being priced differently; different in size, color, carton, grade; having different advertising - it was deemed to be a separate lot. Of each lot of eggs a sample of twenty-four was studied. Each egg was graded for quality and size. Both the quality and weight of the eggs were reported on a dozen basis and the individual-egg basis. When quality ratings were given on a dozen basis it was called the U. S. Consumer basis. This means that the worst 10 per cent of the eggs can lower the grade of the whole lot. The same eggs thus usually would get a lower grade rating on the U.S. Consumer basis than would be indicated by the tabulation of individual eggs. Aithough eggs are technically classed by weight, size and weight are used interchangeably.

No rigid definitions were set up for classifying stores. This was left to the judgment of the interviewer upon consultation with the retailer. The bases for classifications were products handled and services rendered customers.

The term "last week" is used to mean the week prior to the visit to the store. Since stores were visited over a two-month period this may mean any one of the weeks during July and August, 1949. In any event it pertains to a hot-weather period during which egg quality is difficult to maintain.

\section{Quality, Size, and Price}

\section{Genfral Level of Egg Qualities}

About one-fifth of the eggs being offered for sale in the sample of retail stores were of Grade AA quality on Federal standards. (See Tabl 1.) This was considerably higher than the percentage for the Northeast 
Table 1. Quality of Eggs Being Offered for Sale in Retall Stores, Quality Based on Federal, Standards for Individual Eggs, West Virginia, New England, and Northeast in Summer of 1949 *

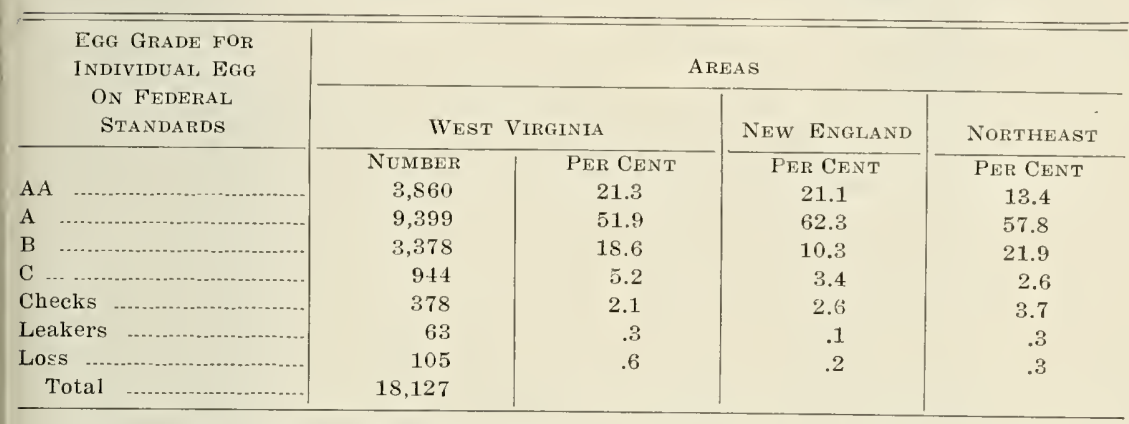

*A minimum of 12 eggs were inspected in any lot and in some states, including West Virginia, at least 24 eggs were inspected.

but about equal to that for New England. When eggs were rated on the basis of the percentage of Grade A plus AA, West Virginia appeared approximately the same as the Northeast in general - about 72 per cent. In this comparison West Virginia fell considerably below New England where 83 per cent of the eggs were found to be grade $A$ or AA. West Virginia did not compare favorably with either area in the percentage of eggs falling below grade B. The variation in quality of eggs in West Virginia stores was greater than in stores of the Northeast - West Virginia having higher percentages of both AA eggs and of eggs below grade $\mathbf{B}$.

In West Virginia, 16.2 per cent of the eggs did not receive a grade because they were checks, leakers, losses, stains, or dirties. For the Northeast this percentage was less than half of that in West Virginia and for New England it was a little over one-fourth. West Virginia retail stores handle less eggs that have been candled and graded in the marketing channels. Consequently it is to be expected that more of the under-grade eggs would still be in the retail store offerings. In fact, comments made by retailers indicated the problem of dirty eggs in West Virginia. More than one-eighth of the eggs found in the retail stores had to be classified as stains or dirties.

Figure 1 shows the relationship of the quality of eggs found in retail stores and the number of eggs sold. For stores selling up to 180 dozen per week, the more eggs the store sold the higher the percentage of the eggs classified by inspectors as Grade AA. There was still a positive relationship between number of dozens sold and quality when both Grade A and AA were added together. In the stores selling more than 


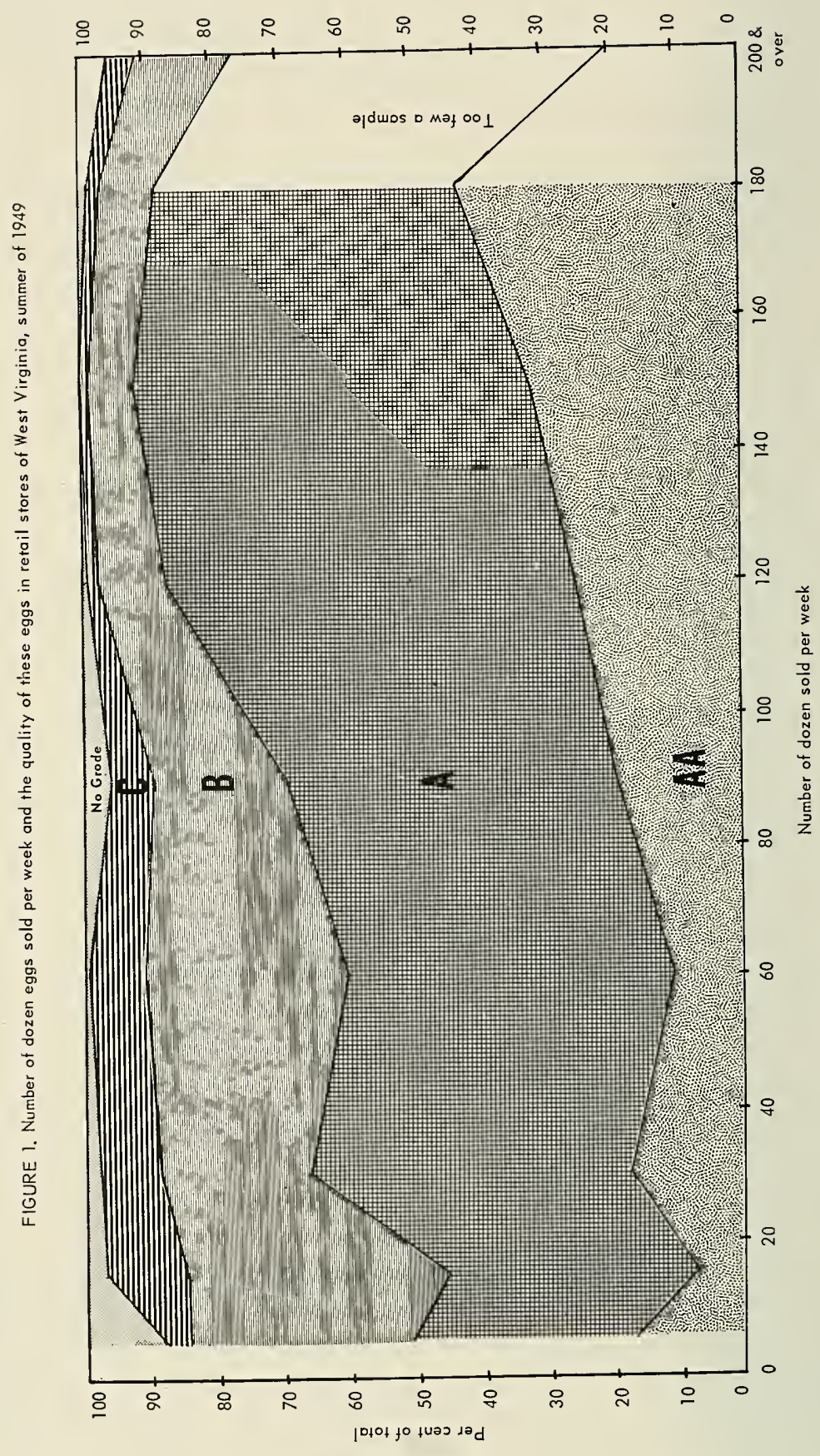


I cases per week (120 dozen), more than 80 per cent of the eggs were Grade $A$ or better. In stores selling less than 2 cases a week, less than 60 per cent were Grade A or better. In stores selling less than 3 cases, about 10 per cent of the eggs were Grade $\mathrm{C}$ or below. In stores that sold 4 or more cases per week, generally not more than 5 per cent of the eggs were of grade $\mathrm{C}$ or below.

\section{Actual Quality and Clamed Quality Compared}

A comparison was made of the quality of eggs retailers said they believed they received and the actual quality they were oftering to customers. Of 94 retailers who said they believed they were receiving eggs of Grade A quality or better, only 50 were offering what was actually Grade A or betier on a U. S. Consumer grade basis. This, however, compares favorably with conditions found in the Northeast. There only about one-third of the eggs the retailers believed were Grade $A$ or better at time of purchase, were Grade $A$ or better when they were offered to customers. In 8 of the 94 West Virginia retail stores the eggs were found to be of a quality lower than Grade $\mathrm{C}$ at the time they were being offered for sale.

\section{Quality Varies with Source of Supply}

Eggs Direct from Farmers Poorer. The source of supply for retailers was studied for 261 lots of eggs. It was found that 46.7 per cent of these lots came directly from farmers and farmers' markets. For the Northeast region, about 35 per cent of the eggs came directly from farmers and farmers' markets. In West Virginia, 36.7 per cent of the lots came from city wholesalers, whereas in the Northeast more than 40 per cent were received from this source. In the sample stores of West Virginia, retailers who were buying directly from farmers and farmers' markets were selling eggs of lower quality than were those who were buying through other marketing chamnels. Retailers who were buying directly from farmers or farmers' markets had only 14.7 per cent Grade A eggs, whereas the average of all retailers' markets had about 25 per cent Grade A eggs. Of the eggs bought directly from farmers and farmers' markets, over one-fifth were of a quality lower than Grade C at the time they were offered for sale. For the Northeast region, about one-sixth of the eggs bought directly from farmers and farmers' markets by retail stores were below Grade $\mathrm{C}$ at the time they were offered to the consumer. In both West Virginia and the Northeast region, it appears that the retail estahlishments that received their eggs from country wholesalers were offering better than average quality to consumers. 
Out-of-State Eggs Better. In 249 stores, retailers gave information as to whether they got their eggs from the near-by area, from within the State but not nearby, from Northeast, or from outside the Northeast. Of these stores, 204 said they were selling eggs obtained nearby. Of the one-fourth who claimed a certain quality, which usually was that they were handling Grade A eggs, about half of the stores were selling eggs of the quality claimed with the other half below that quality. Forty retailers stated they were receiving eggs from outside the state. Of these, six made no claim for quality and thirty-four did. Only about half of the eggs sold by these thirty-four retailers were of a quality as high as claimed. The eggs coming from outside the State graded higher. It should be remembered, however, that this was at a time of year when many of the better local eggs were being sold directly to consumers from farmers and would not enter the retail stores.

\section{Quality and Practices}

Much work has been done to study the effect of refrigeration on eggs. Studies have shown that constant refrigeration is important in preserving egg quality. In the Northeast region it was found that eggs in stores holding them under refrigeration were no better than eggs in stores that used no refrigeration. In West Virginia, however, this was not true. Here 76.4 per cent of the eggs held under refrigeration in the store were Grade A or AA, compared with only 61.5 per cent of the eggs that were not under refrigeration. (See Table 2.) In the Northeast, stores that held eggs under room temperature ordinarily had more frequent delivery and held them for a shorter period than West Virginia stores. In West Virginia 40 per cent of the egg lots held under refrigeration graded A or AA on a U. S. Consumer basis at the time they were offered for sale to consumers, whereas only 19.9 per cent of the lots held at room temperature graded $\mathrm{A}$ or better. Almost half of the egg lots held at room temperature graded $\mathrm{C}$ or lower, but these eggs had been held in the store longer than other lots.

Table 2. Quality of Eggs Under Refrigeration in the Store Comparei With Eggs Not Under Refrigeration, West Virginia, Summer of 1949

\begin{tabular}{|c|c|c|c|c|}
\hline \multirow{2}{*}{$\begin{array}{l}\text { REFrigeration } \\
\text { Practice }\end{array}$} & \multicolumn{4}{|c|}{ EgG QUALITY } \\
\hline & $\mathrm{AA} \& \mathrm{~A}$ & $\mathrm{~B}$ & $\mathrm{C}$ & BELOW C \\
\hline Refrigerated & $\begin{array}{c}\text { PER CENT } \\
76.4\end{array}$ & $\begin{array}{c}\text { PER CENT } \\
16.2\end{array}$ & $\begin{array}{c}\text { PER CENT } \\
5.0\end{array}$ & $\begin{array}{c}\text { PER CENT } \\
2.4\end{array}$ \\
\hline Not refrigerated ..... & 61.4 & 27.8 & 8.3 & 2.4 \\
\hline $\begin{array}{l}\text { Average of both } \\
\text { groups }\end{array}$ & 68.3 & 22.5 & 6.8 & 2.4 \\
\hline
\end{tabular}


Figure 2 shows a general relationship between the egg quality found and the time the eggs had been held in the store. On the average eggs that had been in the store one day contained 83 per cent Grade A or AA. This percentage, however, decreased 6 points per additional day held. Evidently most of these eggs fell to Grade $\mathbf{B}$ quality becausc even at the end of 10 days about 80 per cent of the individual eggs were Grade $\mathrm{B}$ or better.

\section{SIzE OF EgGS}

In the sample stores visited in the survey, the typical size of eggs was that classed as "Large." This class, which ranges from 24 to 27 ounces per dozen, contained 54 per cent of all the eggs weighed. (See Table 3.) For the Northeast this figure was somewhat lower, but since the percentage of Extra Large was higher for the Northeast, the average weights of the eggs in the two areas were not greatly different.

Table 3. Per Cent of Eggs of Different Sizes in the Sample Stores for West Virginia, New England, And the Northeast, Summer of 1949

\begin{tabular}{|c|c|c|c|}
\hline \multirow{2}{*}{$\begin{array}{c}\text { EGG SIZE FOR } \\
\text { INDIVIDUAL EGG } \\
\text { (BASED ON FEDERAL } \\
\text { STANDARDS ) }\end{array}$} & \multicolumn{3}{|c|}{ AREAS } \\
\hline & WEST VIRGINIA & NEW ENGLAND & NORTHEAst \\
\hline 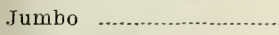 & 5.7 & 2.6 & 4.5 \\
\hline 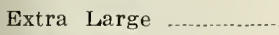 & 24.3 & 14.5 & 30.8 \\
\hline Large & 54.0 & 28.0 & 40.6 \\
\hline Medium & 12.3 & 38.3 & 16.7 \\
\hline Small .............. & 2.7 & 13.5 & 4.8 \\
\hline Peewee & 1.0 & 3.1 & 1.6 \\
\hline$\Lambda$ verage weight per doz. & 25.6 & 23.7 & 25.2 \\
\hline
\end{tabular}

* In the Federal standards the minimum number of ounces per dozen are Jumbo, 30 ; Extra Large, 27: Large, 24; Medium, 21; Small, 18; and Peewee, 15. The individual egg is allowed to fall below the dozen-weight standard to the extent of one ounce per dozen. For example, if a dozen eggs weighs 24 ounces and contains several eggs which would weigh 23 ounces per dozen, the dozen could be classed as Large, but not if it contained any egg weighing at the rate of 22 ounces per dozen. On West Virginia standards a dozen weighing 24 ounces is classed as Large if it weighs at least 24 ounces regardless of the weights of the individual eggs.

In one hundred of the stores studied, retailers made definite claims for the "sizes" (actually lor weights) of the eggs they were offering for sale. On the dozen-weight standard, the only weight standard used for eggs in West Virginia law, five of the one hundred lots of eggs were below standard. Although the total dozen-weight measured up to standards in 95 per cent of the lots, there was considerable variation in size among the individual eggs in the dozen. When the eggs were judged on the Federal standards for individual eggs, 22 per cent of the lots contained eggs small enough to cause the lot to fall below the size claimed. 


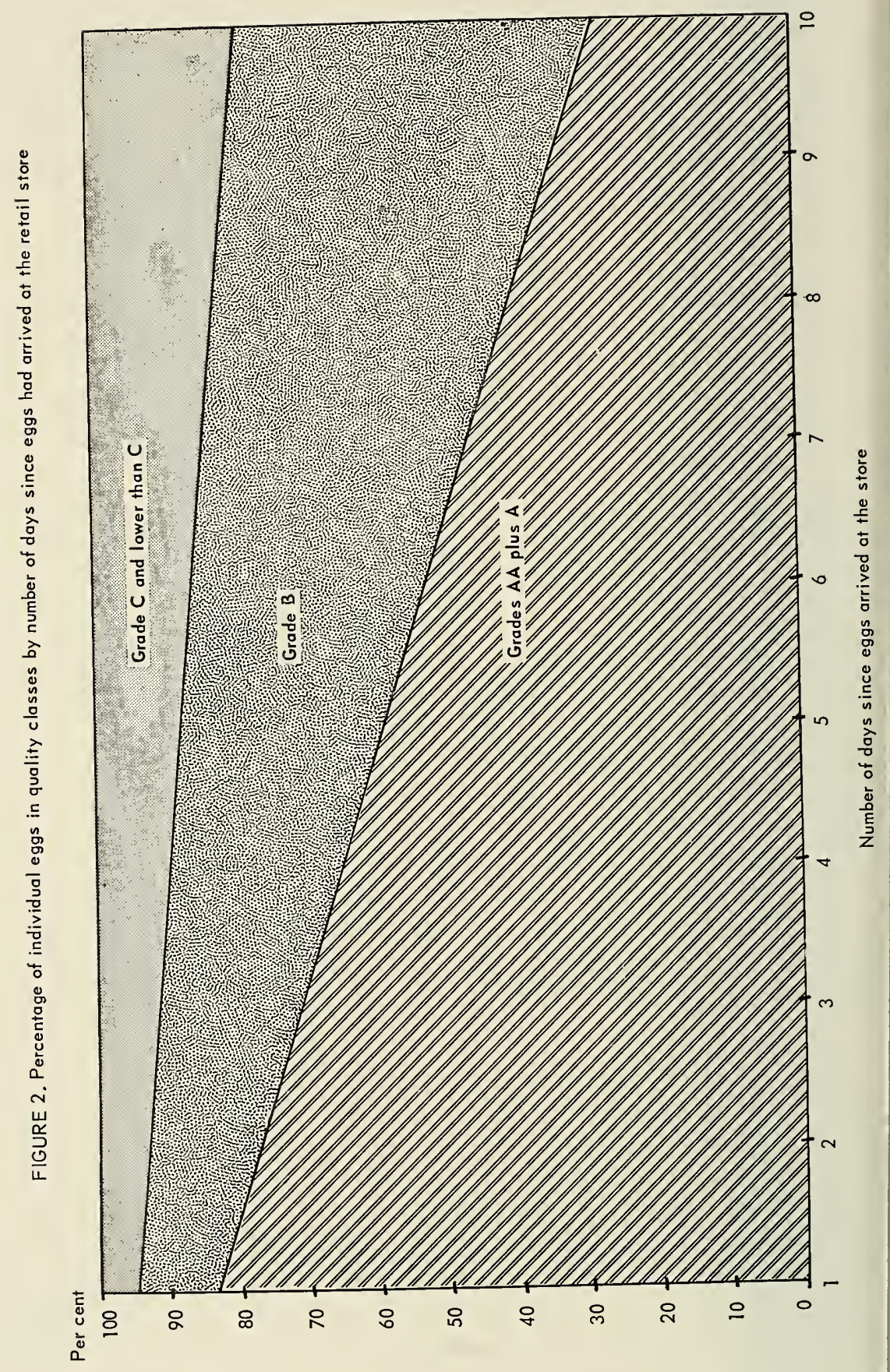


Since the retailers did not claim to be selling on Federal standards, which impose minimum weights for individual eggs, they were under no obligation for the weight of each egg. ${ }^{1}$ It also was true in a sample of the retail stores of the Northeast that a larger percentage of the different lots of eggs fell below the weight class claimed for them when they were judged by the weight of individual eggs rather than by the total dozen weight.

\section{Price to Consuniers}

Egg prices vary considerably from one area to another, depending on the nearness to producing areas and markets. It was found that prices in West Virginia were lower than those in the Northeast. For example, the average price of Large eggs in the Northeast was about 80 cents, whereas in West Virginia it averaged 71.4 cents. In both the Northeast and West Virginia, Medium eggs were priced at an average of about 72 cents.

In West Virginia the smaller egg was relatively overpriced compared with the larger egg. This situation also existed in the Northeast, but not to as great a degree. In eighty West Virginia stores that sold Large eggs, the average price was 71.5 cents a dozen. Seventeen stores sold Medium eggs at 71.3 cents. On this basis, the Large eggs cost the consumer about 45 cents a pound, and the Medium cost about 51 cents. This was at a time of year when large eggs were relatively plentiful. At times of the year when the smaller eggs are plentiful, they may become the better buy on a per-pound basis. Indications are that both retailers and consumers might gain by seeking the sizes that are seasonally or otherwise the better buys on the basis of weight.

Retail Margins on Eggs

The average gross margin per clozen eggs charged by the retailer was about the same for 272 stores in West Virginia as for the rest of the Northeast region. Ten of 259 independent stores charged no margin. Some of these stores paid cash for the eggs they bought, but others gave store credit for eggs bought from customers and assumed they should make their margin only on the goods sold. More than half of the stores that were visited charged a margin of 10 or more cents per dozen in the summer of 1949, but it should be borne in mind that this was at a time when egg prices were high. Except for the few independent stores that charged no margin on eggs, there was no appreciable difference between margins charged by chain stores or independents.

1Although conclusions may yet be premature, indications from a survey of homemakers are that consumers also are rather unconcerned about the size uniformity within the dozen, but do get concerned about the total weight of their purchase. 
Stores were grouped by the cents per dozen they charged as a margin on eggs. It was found that the size of margin alone was not significantly related to the percentage of the store's business accounted for by eggs.

Retailers were asked how they vary the margin they charge on eggs. Forty per cent of the retailers replying to this stated that they do vary the margin. Less than 10 per cent of the stores vary the margin with the supply or price of eggs. Several of the retailers charge lower margins when eggs are higher.

Some stores were classified as general self-service, and others were classified as not being self-service or of the counter-service type. Many were difficult to classify because they gave both counter service and selfservice. These, in this study, were classified as "semi-self." Table 4 gives the data for 182 stores giving counter service. The average margin per dozen eggs in this group was 8.7 cents, compared with 9.8 in the semiself and 10.5 in the stores classified as self-service.

Table 4. Gross Margins Per Dozen Eggs Compared for Stores Rendering Counter, Semi-self, and Seiff-service for All Products Sold, In West Virginia Area, Summer of 1949

\begin{tabular}{|c|c|c|c|c|c|c|c|c|}
\hline \multirow{2}{*}{$\begin{array}{c}\text { Gross Margin } \\
\text { Per Dozen (Cents) }\end{array}$} & \multicolumn{6}{|c|}{ KIND OF STORE } & \multirow{2}{*}{\multicolumn{2}{|c|}{$\begin{array}{c}\text { Total of } \\
\text { ALL Stores }\end{array}$}} \\
\hline & \multicolumn{2}{|c|}{ COUNTER } & \multicolumn{2}{|c|}{ SEMI-SELF } & \multicolumn{2}{|c|}{ SELF-SERVICE } & & \\
\hline $0-6$ & No. & $\begin{array}{c}\% \\
29.1\end{array}$ & No. & $\begin{array}{l}\% \\
10.8\end{array}$ & No. & $\%$ & No. & $\begin{array}{c}\% \\
233\end{array}$ \\
\hline $7-9$ & 35 & 19.2 & 13 & 20.0 & 3 & 12.5 & 51 & 18.8 \\
\hline ............. & 46 & 25.3 & 30 & 46.2 & 10 & 41.7 & 86 & 31.7 \\
\hline 11 and over & 48 & 26.4 & 15 & 23.0 & 8 & 33.3 & 71 & 26.2 \\
\hline Total & 182 & & 65 & & 24 & & 271 & \\
\hline Average margin & & nts & & & 10. & ents & & nts \\
\hline
\end{tabular}

In several stores in which nearly all commodities were handled on a self-service basis, eggs were not available self-service. A sample of 229 West Virginia retail stores showed that eggs were available self-service to the customer in fourteen stores and were handled by clerks in 215 stores. In the fourteen stores the average margin charged per dozen eggs was 10.6 cents, whereas for the counter-service type the average margin was 9.2 cents. This comparison probably is not entirely fair because the small rural store, where retailing eggs is highly competitive with direct sales, is more often of a counter-service type. Also, eggs handled self-service are more likely to be in cartons rather than in paper bags. ${ }^{2}$

$2 \mathrm{~A}$ comparison of margins among stores is difficult because different stores do not render the same service. The retail service on eggs may vary from the minimum of selling and collecting for eggs placed in the store by the "egg man" to that of the retailer even going to farms to pick up eggs. At the time of the survey several retailers who ordinarily would not do so stated that they were willing to drive into the country for eggs if they would know where eggs could be bought. 
On the basis of products handled, the three most important types of stores were "complete food," "grocery," and "general merchandise." For all stores in these three types, the average margin taken on eggs was 9.2 cents a dozen (See Table 5.) Nearly a third of the retailers charged 10 cents a dozen. Both average margins and typical margins varied among these types of stores. In fact, in the grocery and the general merchandise store there seemed to be no typical margin. The margins varied considerably. Almost half of the complete food stores reported that they aimed to get a 10-cent margin on a dozen eggs. These reports tallied closely with accounts of prices paid and prices quoted for eggs on hand. The 10-cent margin was both typical and average for the complete food stores. The average margin for the groceries was 9.3 cents and for general merchandise 8.2 cents a dozen. It is probable that more of the general merchandise stores are in rural areas where margins are likely to be lower. Ten of the ninety-eight general merchandise stores reported they were selling eggs and receiving no margin on the eggs. They were, however, paying for the eggs "in trade." Some of them volunteered that they made the margin on the goods given "in trade" for the eggs. One of the complete food stores and two of the grocery stores handled eggs on a no-margin basis. At the time of the survey no store was found selling eggs at a price lower than the price paid, but egg prices were not declining at the time.

\section{Merchandising Eggs In Retail Stores}

Volume of EgG Sales

In West Virginia, information on the egg volume handled was obtained in 303 retail stores. On the average these stores sold 71.6 dozen eggs the week prior to the visit to the store by the field worker. Less than 1 per cent of the stores sold more than four hundred dozen eggs during the week, whereas more than three-fourths sold less than one hundred dozen. The average per store was less than that found for the Northeast, but the average for the Northeast was increased because there were several extremely large stores in the sample.

The egg volume varied among different types of stores. Eighty-seven complete food stores averaged 83.9 dozen eggs sold "last week" compared with 40.6 dozen in the grocery stores and 64.2 dozen in the general merchandise stores. Although grocery stores averaged less than half as many eggs sold as did the complete food stores, eggs accounted for a larger percentage of their sales. Grocery stores averaged about 10 dozen cggs per $\$ 100$ gross sales, whereas complete food stores averaged 4.4 dozen per $\$ 100$ gross. The average dollar volume of the complete food stores 

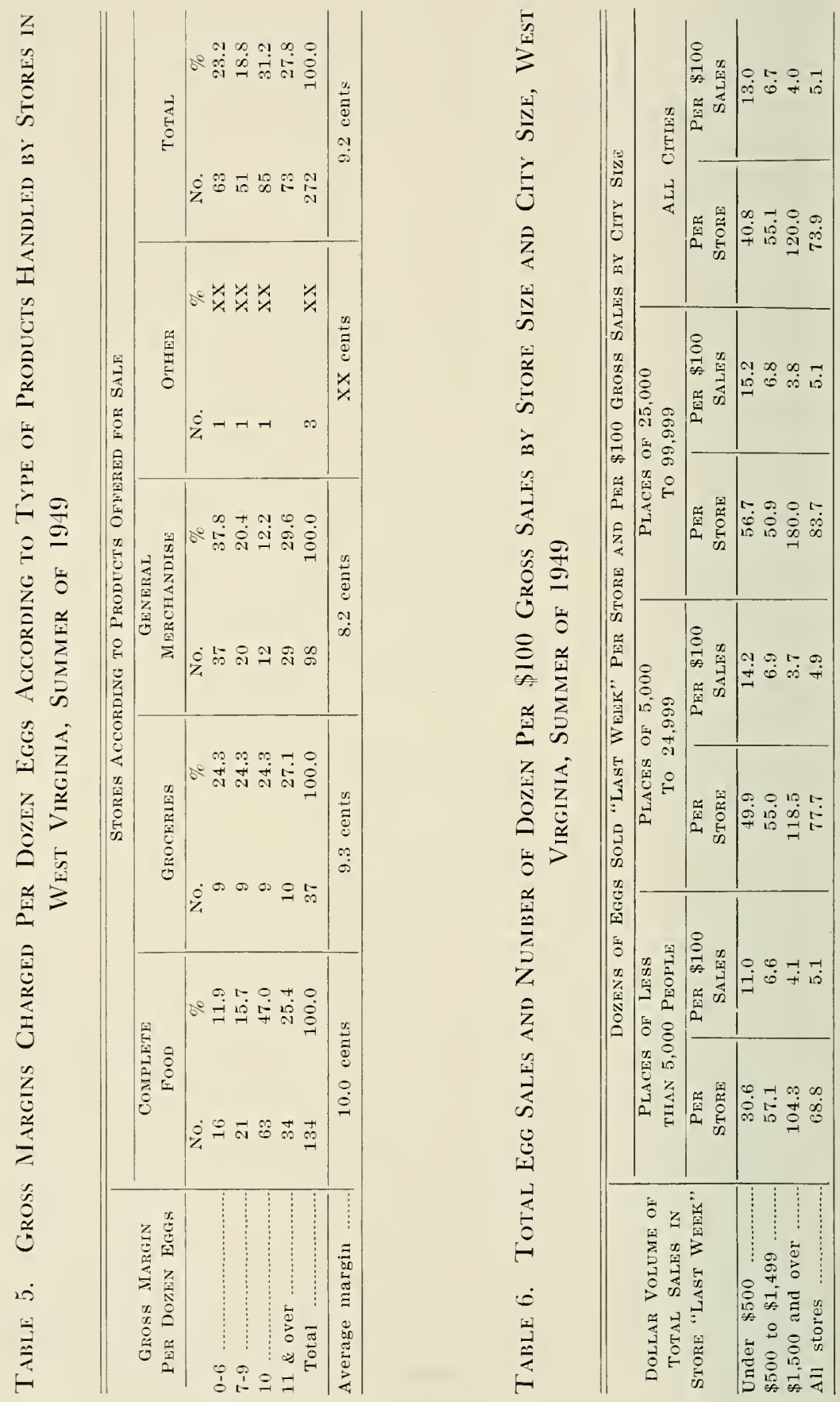
was nearly five times as large as the average for the grocery stores. The complete food stores carry more items. Thus egg sales become a smaller percentage of the total sales.

In both the complete lood stores and the general merchandise stores, eggs accounted for less of the total sales in the larger stores than in the smaller ones. These are averages with a considerable variation among indiviclual stores.

The amount of eggs sold by a store was associated with the size of the city in which the store was located. The sampled stores in places with less than 5,000 people averaged 68.8 dozen eggs sold "last week," compared with 77.7 dozen in stores in cities of 5,000) to 24,999 and 83.7 in West Virginia cities of over 25,000 or over. (See Table 6.) Part of this was the result of larger stores in the larger places, but all the difference was not explained by this alone. Generally-although not without many exceptions-stores with equal total dollar volume seemed more likely to have a larger egg volume if they were located in larger cities. All stores in the sample averaged 5.1 dozen eggs sold per $\$ 100$ of gross sales.

\section{LOCATION OF DISPLAY}

Of 248 stores in which the volume of total egg sales and the location of the egg display were both known, 143 displayed eggs in the rear of the store. Only 28 stores displayed eggs in the front part of the store. The remainder were split about evenly between right and left sides of the store. It seems that few stores "place" eggs in a prominent display position. Ninety-one of 248 stores had eggs displayed by themselves, 84 had them adjoining meats, 33 had them adjoining dairy products, and 11 placed them between meats and dairy products. None of the stores selling more than 200 dozen a week had eggs adjoining fruits and vegetables, but 13 of the small stores selling less than 100 dozen had them located near fruits and vegetables. Since eggs take on the flavors of certain fruits and vegetables, it would not be considered advisable to have eggs in or too near these products.

\section{Retail Containers Used}

The paper bag was found to be the most common container in which the consmmer carried eggs out of the retail store:" One humdred

$\therefore$ As mentioned earlier in the report the few extremely large stores of the state were inadequately sampled and their inclusion might have altered some of the estimates for the State. It is probable that inclusion of these few larger stores would have decreased sliglitly the percentage of eggs sold in paper bags and would have increased slightly the percentago of eggs sold in the "long" 2 by fi carton. However, even though large, these stores are few enough in number so the figures probably would not have been changed greatly with a more complete sample or a complete enumeration. 
sixty-nine of 249 stores sold eggs in paper bags. These were smaller-thanaverage stores. Only about hall of the eggs in the sample stores were sold in paper bags. (See Table 7.) In the Northeast less than one-fifth of the eggs were retailed in paper bags.

Table 7. Number of Dozen Eggs Sold in Different Types of Containers in Sample Stores of West Virginia, Summer of 1949

\begin{tabular}{|c|c|c|c|}
\hline CONTAINER* & $\begin{array}{c}\text { NUMBER } \\
\text { OF STORES }\end{array}$ & $\begin{array}{l}\text { PER CENT } \\
\text { OF STORES }\end{array}$ & $\begin{array}{l}\text { PER CENT OF } \\
\text { DOZEN SOLD }\end{array}$ \\
\hline 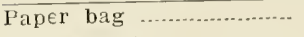 & 169 & 67.9 & 50.2 \\
\hline Square carton & 41 & 16.4 & 28.0 \\
\hline Long carton ........................ & 39 & 15.7 & 21.8 \\
\hline
\end{tabular}

* The square carton las three rows with four eggs in each row. The long carton has two rows with six eggs in each row.

The "square" carton was more prevalent than the "long" carton in West Virginia. (See footnote under Table 7.) In the Northeast 51.2 per cent of the eggs were retailed in long cartons compared with only 21.8 per cent for West Virginia. Prevalence of square cartons was about the same in both areas. The long carton usually is more expensive than the square carton. West Virginia stores used less expensive retail containers than did stores in the Northeast.

\section{Some Suggestions Made by Retailers}

Retailers were asked what suggestions they had that the Agricultural Experiment Station might pass back to egg producers and deaiers. The suggestion most frequently made was that they would like to be able to get cleaner eggs. Next, and of about equal importance, were the appeal for freshness and size. Two other items, but not mentioned nearly a: often, had to do with much better quality and better cartoning. Severa retailers stated that they would be well served if somebody woulc merely tell them where to find eggs. About two-fifths of the store sampled were out of eggs at the time of the visit. Nearly all of thes stated that their problem of finding eggs is limited to periods when egg are scarce. 

